\title{
Science information literacy and the role of academic librarians
}

Have you ever noticed, when you teach, that the moment you start
sharing a personal story with your students, they instantly snap to
attention? You understand the value of stories. But some teachers
don't insert many stories into their lessons, because they're worried
that they don't have gripping stories to tell, or that they aren't good
story tellers. So maybe it's worth identifying which kinds of stories are
effective in making ideas stick. The answer is this: virtually any kind.
Chip Heath \& Dan Heath (Made to Stick: Why Some

Ideas Survive and Others Die, 2010)

\subsection{Is there a future for information literacy instruction?}

With the number of reference questions decreasing, most journals being available online, and database interfaces becoming more user-friendly, what is left for subject/ liaison librarians to do? As information, research, and education are becoming increasingly digital, academic libraries are forced to redefine their role in supporting education and research. Teaching information literacy is a major responsibility for subject/liaison librarians, but advances in information retrieval systems, such as improved natural language searching and Semantic Web, could change their role in this area. This new environment is particularly challenging for librarians who were trained to provide traditional library services.

A Delphi study based on a survey of 13 information literacy experts looked at the possible changes in information literacy and the role of librarians in it in the next ten years (Saunders, 2009). The study developed three possible scenarios for the future of library instruction services and tried to answer the following questions:

How prevalent will information literacy programs be within the higher education curriculum? Will academic librarians and library organizations play a significant role in the instruction and assessment of information literacy skills? If so, in what area(s) will they concentrate? Lastly, will their role be diminished as teaching faculty take on more of the responsibility for integrating this instruction into their own curricula?

The first scenario adhered to the "status quo," in which the situation remains as it is now. According to the second scenario, teaching faculty will take over instruction and assessment of information literacy, a development that will leave librarians marginalized. The third scenario envisioned a close collaboration between faculty 
and librarians in sharing information-literacy responsibilities. Most respondents to this survey showed optimism about the future of information literacy in academia and believed that librarians will continue to have a role to play through collaboration with faculty. The possibility that librarians could be replaced under certain circumstances has not been excluded, though, mainly because the improved and more intuitive information retrieval systems could make learning many information literacy skills unnecessary.

Departments have unique cultures, but there is also a specific culture in every university. An article discussed the importance and the difficulty of creating "a pervasively collaborative culture required by information literacy programs" and recognized that organizational culture plays a role in "campus readiness for information literacy" (Bennett, 2007). Another article suggested that librarians should avoid sticking to "a library-centric program and set an information literacy path that is relevant and valuable to course instructors and is aligned with the educational goals and mission of their institutions" (Brasley, 2008). It also described a possible framework for collaborations between librarians and teaching faculty that could lead to successful information literacy programs. Establishing partnerships between librarians and faculty, embedding librarians in academic units (Olivares, 2010), and providing online instruction (McMillen and Fabbi, 2010; York and Vance, 2009) will allow librarians to continue to play an important role in information literacy.

As suggested by Travis, in order to achieve integration of information literacy into the university curriculum, librarians and faculty need to investigate theories of change. He examined the change agency theory as a tool and a process for integrating information literacy into the general education curriculum (Travis, 2008).

The major obstacles for librarians to overcome in preserving their dominant role on the information literacy front would be faculty attitudes, lack of subject expertise, lack of technical skills, and a constantly changing dynamic environment that requires reskilling and lifelong learning (Brewerton, 2012). Librarians need to prove that their contribution to education is valuable. The number of instruction sessions is not a realistic measure of student learning, and librarians are still struggling to find a better way for assessing the impact of their efforts. By demonstrating improvement in student learning as a direct result from their instruction, librarians would be better able to justify their instructional programs.

\subsection{The many faces of information literacy}

The lack of consensus on how to define information literacy is at the root of the problems confronting librarians. Discipline and organizational cultures play a role in how information literacy is understood and valued (Saunders, 2009). In the future, teaching how to search and access information, which is the currently predominant model for library instruction, will become less important. If information literacy is to survive as a concept, it would need to include areas that until now either have not been supported by librarians or are the result of recent developments 
in technology, research, and scientific publishing. Moving away from teaching information retrieval skills in favor of providing training on managing scientific information and research data will be a great opportunity for librarians to continue to be important players in the field of information literacy. Incorporating data literacy, bibliographic management, scientific writing, and ethics of scientific communication under the umbrella of information literacy will allow librarians to find new important roles in supporting education and research in their organizations. The next sections of this chapter show how bibliographic management programs were successfully integrated in information literacy programs. The different formats (faceto-face sessions and online tutorials) and tools (LibGuides and SurveyMonkey) were used to make the teaching of information literacy and assessment of student learning more efficient.

\subsection{Managing citations}

Bibliographic management tools have been widely used by researchers and students to import, store, organize, and manage references that they can later use when writing research papers, theses, dissertations, journal articles, and other publications. As shown in the next sections, incorporating them into information literacy classes was very beneficial to students.

\subsubsection{What bibliographic management programs allow us to do}

- Easy storage of references found online

- Discovery of new articles and resources

- Automated article recommendations

- Sharing of references with peers

- Finding out who's reading what you're reading

- Storing and searching of PDFs

- Capturing references

- Inserting citations from an individual's library into a paper

- Viewing from anywhere

- Viewing saved references, along with the PDFs, on web, desktop, and mobile applications

- Taking notes and annotating articles in your library

- Automatic extraction of metadata from PDF papers

- Back-up and synchronization across multiple computers and with an online account

- PDF viewer with sticky notes, text highlighting, and full-screen reading

- Full-text search across papers

- Smart filtering, tagging, and automatic PDF file renaming

- Shared groups to collaboratively tag and annotate research papers

- Public groups to share reading lists

- Social networking features

- Usage-based readership statistics about papers, authors, and publications

- Smartphone apps

- Inserting citations from your library in a document you are writing 


\subsubsection{Most popular bibliographic management programs}

The number of reference management tools is growing, and in order for users to decide which tool is best for them, they need to take into consideration many factors. Many websites and articles provide technical specifications and comparisons for these programs that help users choose the best tool for their specific needs (DuarteGarcia, 2007; Fenner et al., 2014; McKinney, 2013; Zhang, 2012). Sometimes, one tool can be used for one purpose and another one for a different purpose. Quite often, choosing a bibliographic management tool is often a matter of personal preference.

Some of the most popular bibliographic management programs are listed below:

- CiteULike (www.citeulike.org)

- Colwiz (www.colwiz.com)

- EndNote Online (www.myendnoteweb.com)

- EndNote Desktop (www.endnote.com)

- Mendeley (www.mendeley.com)

- Papers (www.papersapp.com)

- ReadCube (www.readcube.com)

- RefWorks (www.refworks.com)

- Zotero (www.zotero.org)

EndNote, Mendeley, and Zotero are the most widely used bibliographic management programs in academic institutions, and they are discussed in more detail below.

\subsubsection{EndNote (Thomson Reuters)}

www.endnote.com

EndNote Desktop is a commercial reference management software package used to manage bibliographies and references when writing articles, books, theses, and other documents.

www.myendnoteweb.com

EndNote Online (previously, EndNote Web) is a free web version of EndNote (Duarte-Garcia, 2007; McKinney, 2013; Thomson Reuters, 2014; Zhang, 2012). Users can synchronize their EndNote Online account with the desktop version.

\subsubsection{Mendeley (Elsevier, Inc.)}

\section{www.mendeley.com}

Mendeley is a desktop and web program for managing and sharing research papers, discovering research data, and collaborating online (Habib, 2014; Haustein, 2014; Zhang, 2012). It combines Mendeley Desktop, a PDF and reference management application (available for Windows, Mac, and Linux), with Mendeley Web, an online network for researchers. Mendeley requires the user to store all data on its servers. Upon registration, Mendeley provides the user with $1000 \mathrm{MB}$ of free space, which is upgradeable at a cost. 


\subsubsection{Zotero}

WwW.zotero.org

Zotero is free, open-source software for managing bibliographic data and related research materials (e.g. PDFs). Its features include web browser integration (with Firefox), online syncing, and citing while writing. Zotero Standalone allows Zotero to be run as an independent program outside Firefox. You can add everything to ZoteroPDFs, images, videos, and snapshots of web pages.

\subsubsection{Choosing a bibliographic management program}

While it is important to know each tool's strengths and weaknesses, this is not the only consideration that should influence your decision. There are many websites and articles comparing the functionalities of these tools (Fenner et al., 2014; Wikipedia, 2014; Zhang, 2012), but many of these comparisons look like the technical specifications for software or hardware that you can see when looking for a digital camera or another electronic product.

For those who use Web of Science or PubMed most of the time, EndNote is probably the best tool. It is made by Thomson Reuters, which also publishes Web of Science and is optimized to work with it. EndNote provides the greatest number of citation styles (more than 5000), but this could be an advantage over the other bibliographic management tools only if you need access to many different citation styles. EndNote or Mendeley will be better options than Zotero when using other browsers than Firefox, because Zotero works best as a Firefox extension. Those who want to use EndNote Desktop have to purchase the software and install it on their computers.

Mendeley is designed to be an academic networking tool as well as a platformindependent citation management tool that syncs your data across all your computers. It would be the best choice if sharing with a network of people and finding out what citations other people are compiling in their libraries is important to you. Students tend to prefer programs that look like the social media sites they are using, and the creators of bibliographic management tools are listening, adapting to the needs and preferences of these new users. Mendeley's more "modern" interface emulates the experience they have with other social networking sites.

The more innovative feature of Mendeley, which distinguishes it from other bibliographic management programs, is that it aggregates and displays all users' citations so that users can search or browse across the entire set of citations to find resources related to their research and then add them to their own citation library for further customization. Although Mendeley maintains users' privacy, this feature may cause concerns among researchers involved in competitive areas of science who do not like their information-gathering habits to be monitored by a company.

Zotero and Mendeley allow the capture of a screenshot of a web page as well as other data about it. Syncing citations to an online Zotero account is easier and works more smoothly than syncing EndNote Desktop with EndNote Online. Zotero's capture function works with more resources (databases, catalogs, and websites) than the import function of Mendeley or the capture feature of EndNote. Users can also import citations from sites such as Amazon and Flickr. Zotero makes it easy to create tags and write notes assigned to citations. 
Very often, people choose a particular bibliographic management tool because they find it easy to use. As discussed in an article, there are also generational preferences with regard to which programs people are choosing (Hull et al., 2008).

\subsection{Designing information literacy instruction}

The introduction of LibGuides by Springshare (www.springshare.com) in the last few years has allowed libraries to promote their information resources in a new way using multimedia and social networking tools. LibGuides are much more flexible to use than web pages controlled by rigid rules and other external (institutional) factors. For the last several years, I have been using LibGuides in teaching scientific information and bibliographic management tools (Baykoucheva, 2011). For every course in which I taught such classes, I prepared a page in a LibGuide (http://lib.guides.umd.edu/chemistryresources), in which individual course pages were listed under a tab called "Course materials." Such pages were used by students to access all resources taught in class. The assignment for the class (SurveyMonkey was used for this), a detailed handout providing essential details about search strategies, and other class-related information were also posted on the LibGuide page.

Integrating bibliographic management programs in science literacy classes allows students to learn how to do two important things: (1) perform literature and chemical property searches efficiently and (2) use a bibliographic management program to store references and cite them while writing. Classes were held in undergraduate and graduate courses in chemistry, biochemistry, molecular biology, and nutrition, as well as in a Professional Writing Program and in several honors programs.

Figure 6.1 shows a LibGuide page (http://lib.guides.umd.edu/chem272) created for a large chemistry course (CHEM272) for nonmajors with 454 students, divided into 22 sections. Teaching assistants (TAs) were trained to teach the instruction sessions for each section and grade the online assignments that students had to complete. In one hour, in addition to learning how to search literature databases, students also acquired basic knowledge of how to import references from databases into EndNote and insert citations (Cite While You Write) from their EndNote libraries into documents they were writing. Besides learning how to find and filter literature, students explored several chemistry property databases, drew molecular structures, searched for chemical compounds that corresponded to these structures, and found chemical properties and reactions for these compounds.

EndNote was used in these classes only as an example of a bibliographic management program. Once they have learned how such a program works, students can decide whether to use it or choose another tool. Zotero, Mendeley, and other new tools are free and easy to use.

\subsection{How do we know we are helping students learn?}

Each student had to complete an online assignment in SurveyMonkey. The assignment was graded and the grade was part of the overall grade of the student for the course. All students submitted their assignments and were very successful in answering the questions. It was very important that attendance and assignment were mandatory, which made the information 


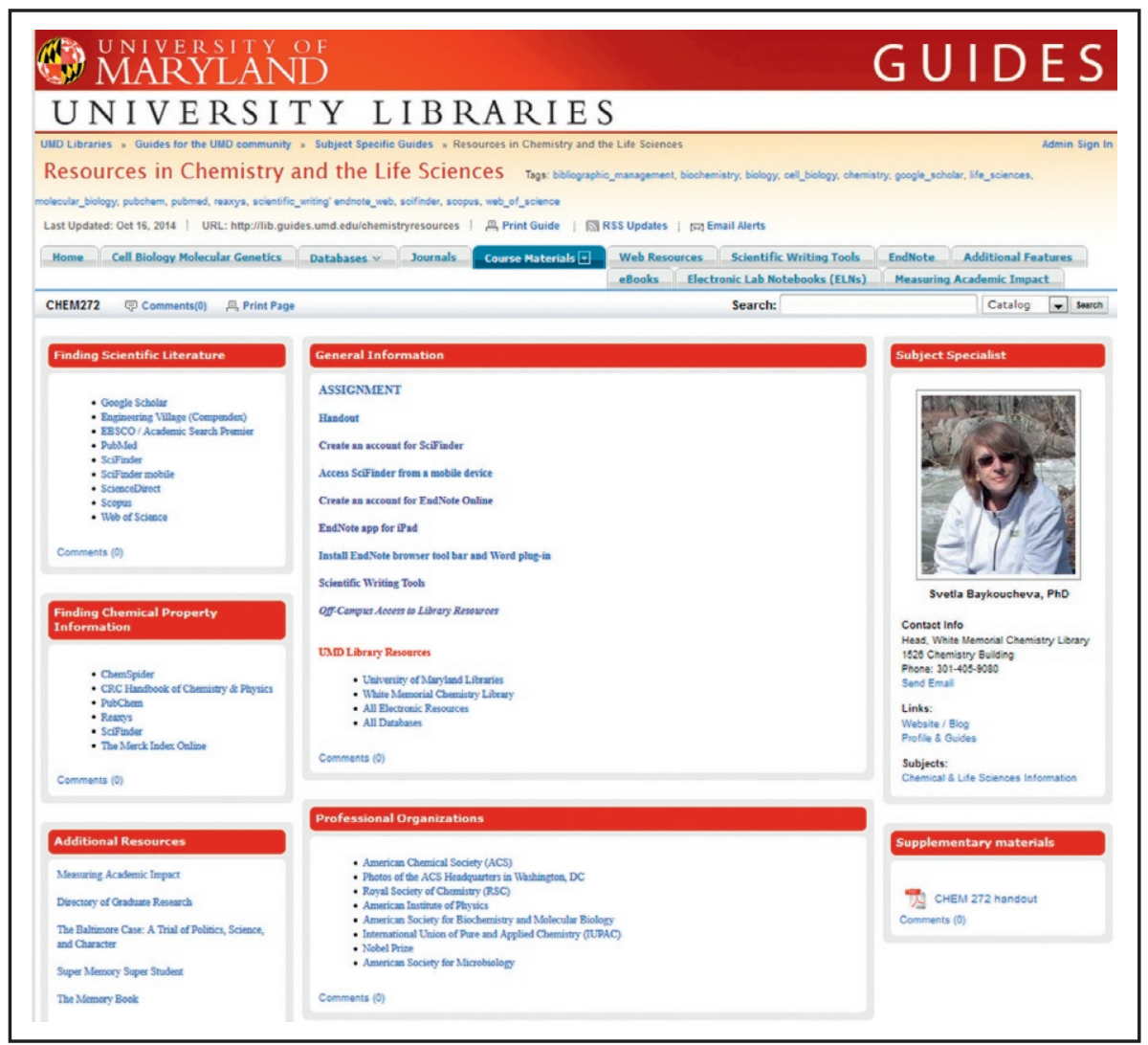

Figure 6.1 A page in a LibGuide used for teaching information literacy in an undergraduate chemistry course. The 456 students enrolled in the course were divided into 22 sections. The grades were part of the overall grade of the students for the course.

literacy class part of the whole course. As many students have acknowledged, the assignment enforced what they had learned in class and enabled them to practice with the resources and the bibliographic management program on their own. The fact that the assignment was graded and that the grade was part of their overall grade for the course was very important, as this motivated students to do it and do it as well as they could. This has substantially increased the significance of the library instruction in the eyes of both students and faculty. Now, all instructors with whom I have collaborated in incorporating information literacy classes in their courses always ask me to include an assignment and to cover EndNote.

One of the questions in the assignment required students to rank five of the resources taught in class (\#1 being the most useful one). These resources were EndNote, PubMed, Reaxys, SciFinder, and Web of Science. As Figure 6.2 shows, 142 students (31\%) have ranked EndNote as the most useful resource; Reaxys was ranked as the most useful resource by 163 students (36\%). These results show that students realized that a bibliographic management program is very useful to them. After the successful experiment with this 200-level course, we are looking into rolling out a similar information-literacy class in a freshman chemistry course with 800 students. 


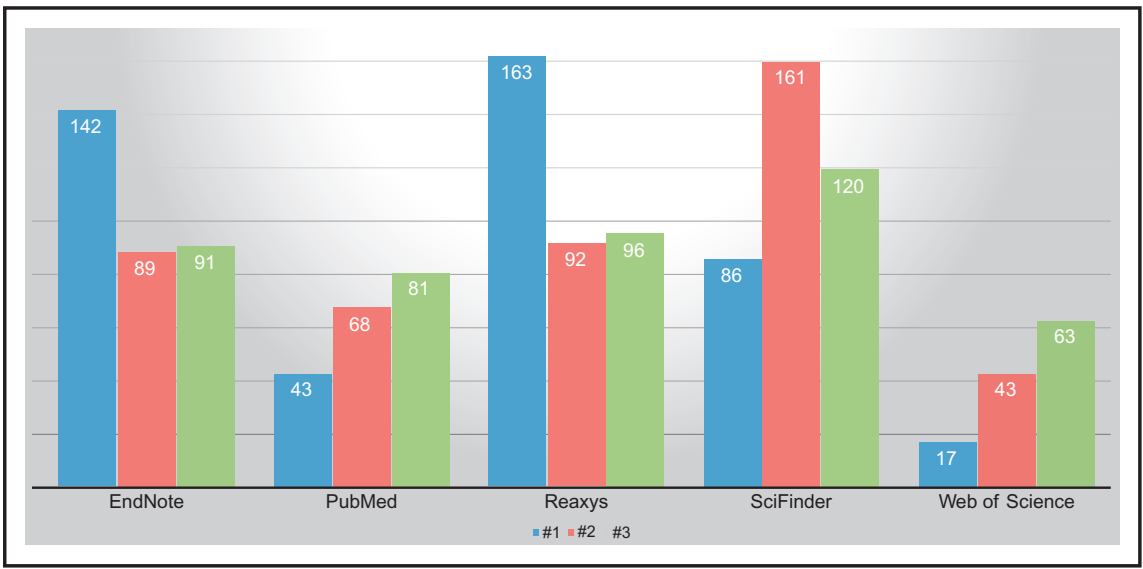

Figure 6.2 Ranking of resources by students in an undergraduate chemistry course. Students were asked to rank the three resources they had found most useful from the following ones that were taught in class: EndNote Web, PubMed, Reaxys, SciFinder, and Web of Science. EndNote was ranked as the most useful resource by 142 students $(31 \%)$. The resource that was found most useful by the majority of students was Reaxys, with 163 students (36\%) giving it this ranking. There were 456 students in the course, divided into 22 sections.

Students in a graduate chemistry course had to answer a similar question in their assignment. As Figure 6.3 shows, there were some differences in the preferences of students. While EndNote had similar ranking (33\% of students selected it as the most useful resource), the scientific database that graduate students ranked as the most useful one was SciFinder, with $38 \%$ of students giving it this ranking.

The students in the undergraduate course chose Reaxys as the most useful resource. It is difficult to explain these differences, but it would be interesting to explore the reasons for them. It could be that the students have made these choices based on their immediate needs (e.g. other course assignments and what material their course was covering). It was interesting, though, to see how students perceived what they were taught and see them try to figure out which resources would benefit them most. It was not a surprise that students in a chemistry course ranked the chemistry databases SciFinder and Reaxys as the most important ones. What is really interesting is that they gave a bibliographic management program such a high ranking. This proves that bibliographic management should be an important component of information literacy and that students need to be exposed to these tools as early as possible.

\subsubsection{What usage statistics tell us}

The statistics provided by the LibGuide mentioned above show that the peaks in its usage coincided with the classes and assignments. As shown in Figure 6.4, the LibGuide was accessed 19,118 times in the year 2014. The two peaks of use (in April and September) coincided with classes that were taught in a large chemistry course (CHEM272) with 456 students, who had to access all resources through the 


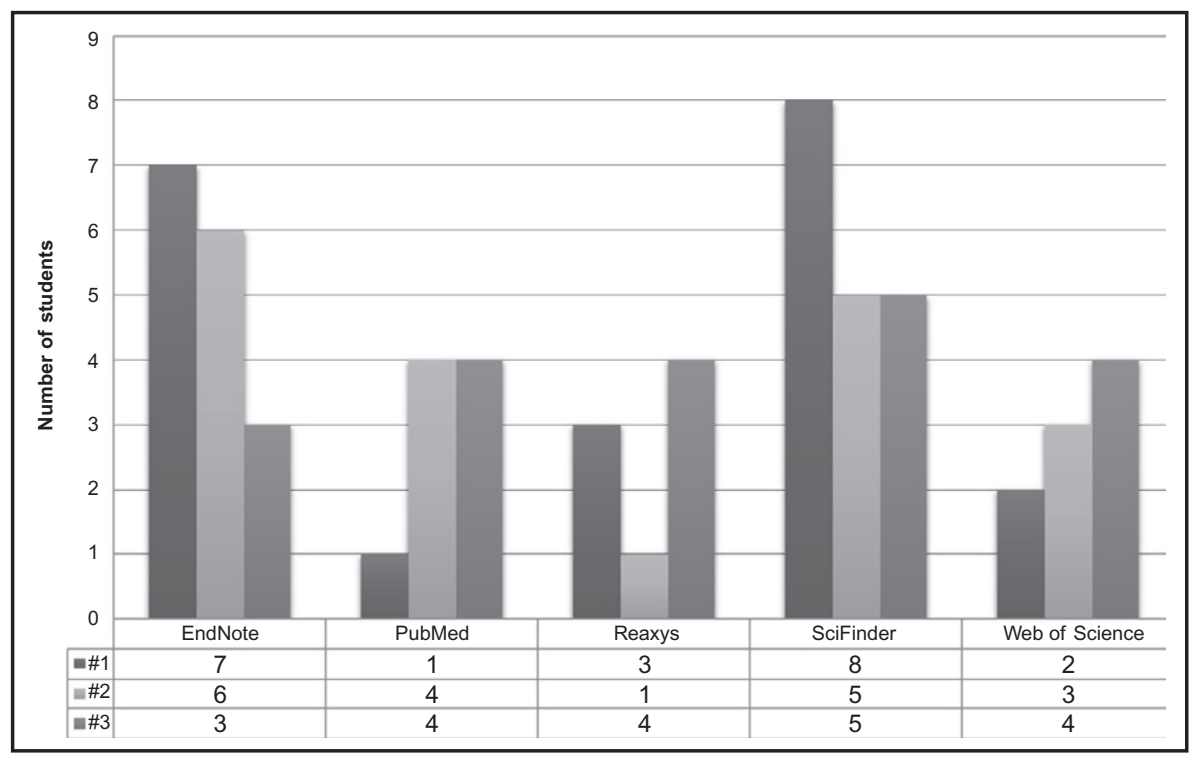

Figure 6.3 Ranking of resources by students in a graduate chemistry course (October 2014). EndNote was ranked as the \#1 (most useful) resource by $33 \%$ of students and was second only to SciFinder in this respect.

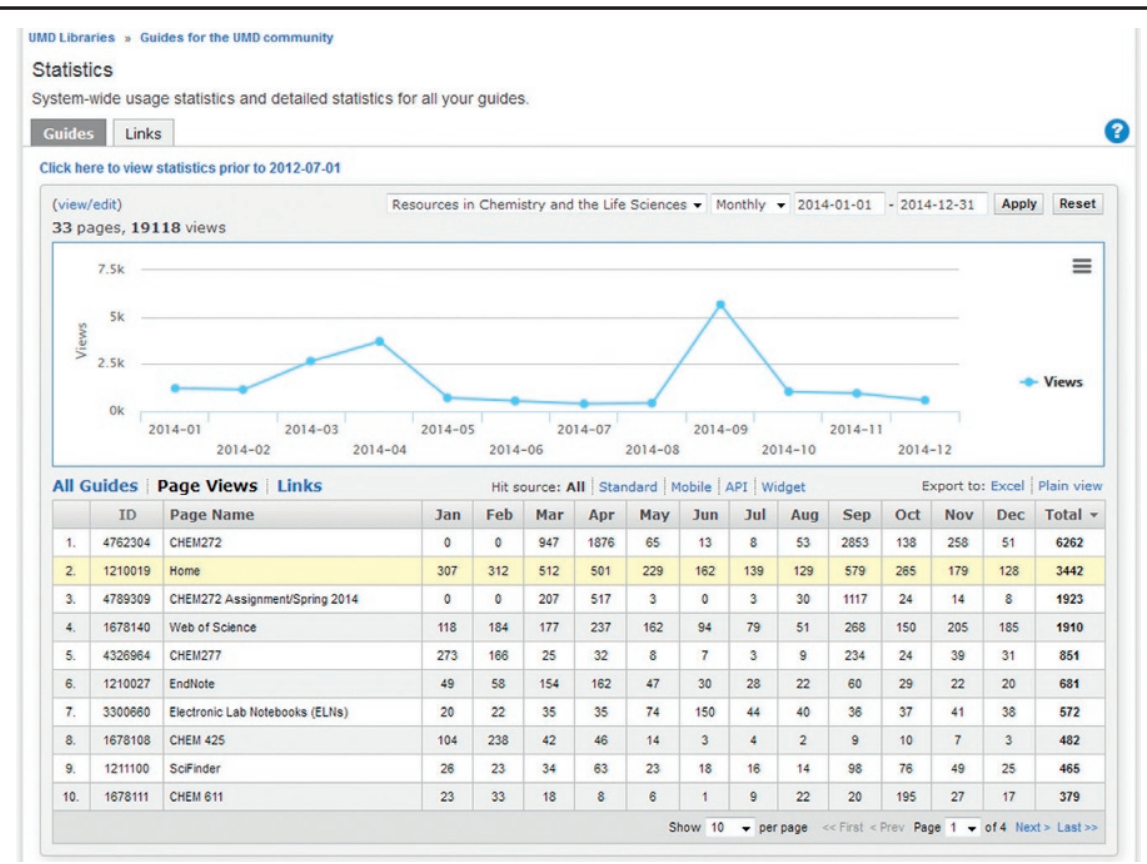

Figure 6.4 Usage data for a LibGuide (http://lib.guides.umd.edu/chemistryresources) used by the author to teach scientific information and bibliographic management in chemistry and other courses at the University of Maryland College Park. As shown in the graph, the LibGuide was accessed 5546 times during the month of September 2014. 
LibGuide. Particularly remarkable are the results for the month of September, when the LibGuide was used 5674 times. In the course of 12 months (from June 2013 to May 2014), the highest usage of the same LibGuide happened in October 2013 and April 2014 (Figure 6.5), which also coincided with classes and assignments. When the LibGuide stats were compared with the usage stats for SciFinder (Figure 6.6),

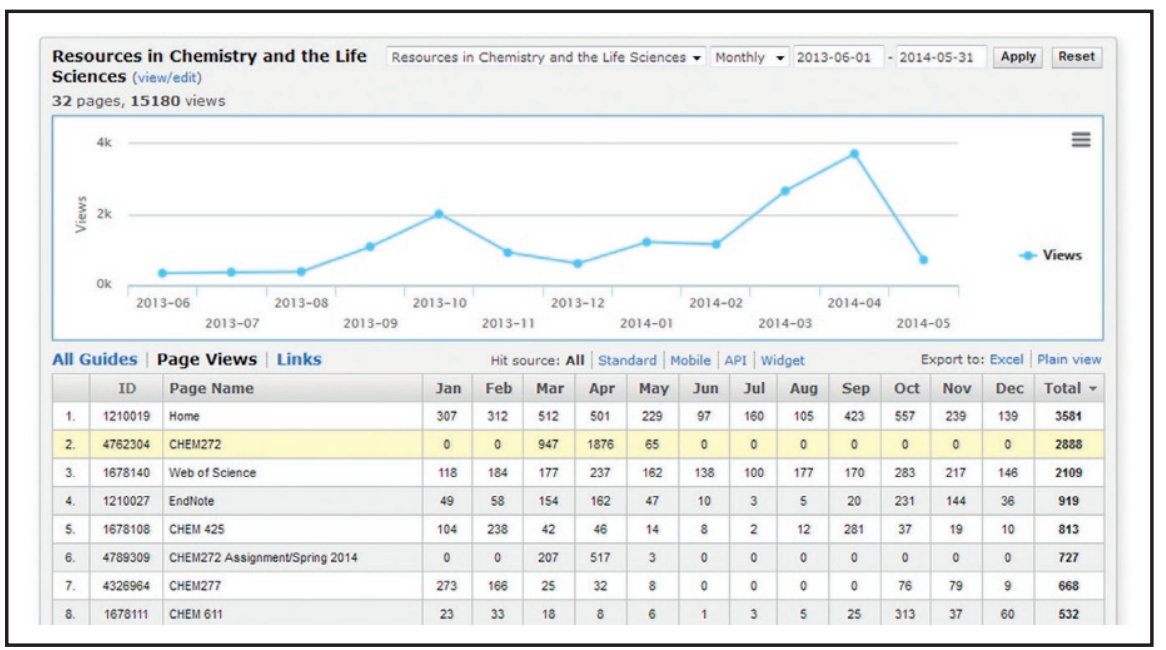

Figure 6.5 Usage statistics for a LibGuide used in teaching scientific information and bibliographic management in courses at the University of Maryland College Park during the period from June 1, 2013, to May 31, 2014.

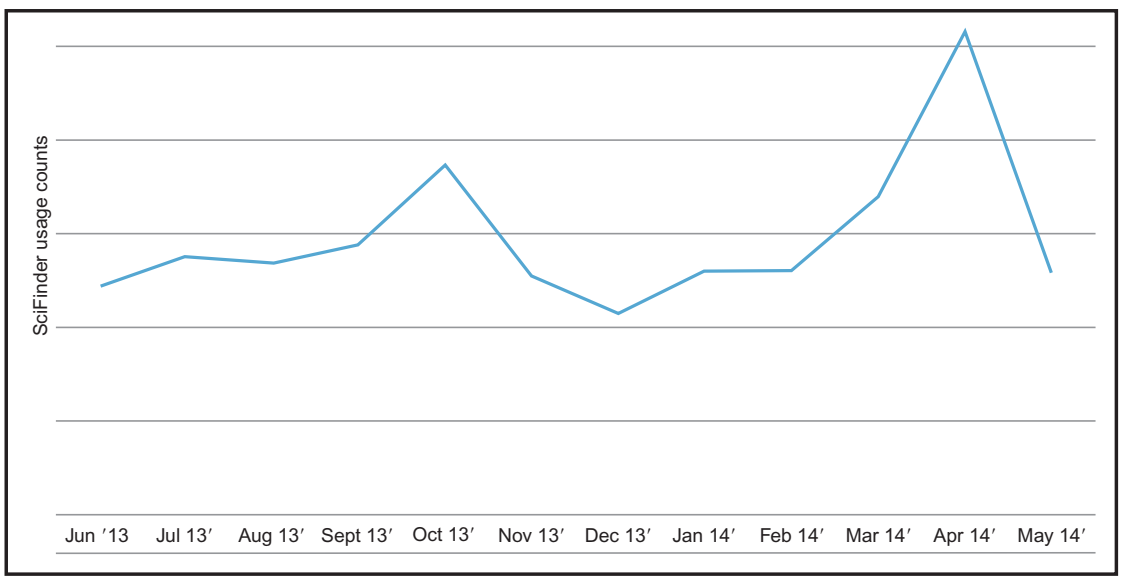

Figure 6.6 The peaks in SciFinder usage in October 2013 and April 2014 for the University of Maryland College Park coincided with the highest peaks in the access to a LibGuide used for teaching. 
it was found that the times when the LibGuide was used most coincided with the highest usage of SciFinder, one of the databases students had to use in class and for their assignments.

Having statistics of this kind to present can benefit librarians who are trying to find more accurate metrics than the number of classes taught, to prove their value. Results like these could help them demonstrate that their teaching is having an impact on the use of library resources and, consequently, on the information literacy of students.

As Figure 6.4 shows, the LibGuide also provided information about which particular areas were most often used by students. In this particular case, the highest usage was registered for the course page of the large chemistry course (CHEM272), from which students accessed all databases, the assignment, and the handout, along with other materials posted for the course.

\subsection{Assessing student learning}

For many years, I have been using SurveyMonkey for online assignments in the courses I have taught. Having all assignments in SurveyMonkey has allowed me to keep hundreds of assignments from which I was able to reuse questions and go back and use the results for reports, papers, and adjustment of teaching strategy. I was also able to see the learning outcomes of the whole group of students, as well as the individual results. The assignments were graded, and the grades were included in the overall grade of the student for the whole course. The number of classes and their duration differed from course to course-from 50 minutes to three hours duration and from one class in a course to three classes in consecutive weeks. The assignments included from 10 questions (for undergraduate courses) to 20 questions (for graduate courses). Figures 6.7-6.10 show some examples of the questions and how the students, as a group, responded to them.

\subsection{Instruction formats}

There is a discussion among librarians about what formats would best suit students, instructors, and researchers in supporting information literacy. The main question that is asked is whether face-to face (F2F), entirely online instruction, or a blended format (both F2F and online) would be the most productive and efficient. As the results from surveys in my classes have consistently shown, the format students most preferred was the F2F format, as they found it easier to follow instructions in class and liked to be able to ask questions. Attending these classes was mandatory, and having an assignment that was graded motivated students to learn as much as possible in class, so that they could later do the assignment.

In the assignment, students had to answer a question about the preferred format of information literacy classes. More than $65 \%$ preferred F2F instruction; around $30 \%$ 


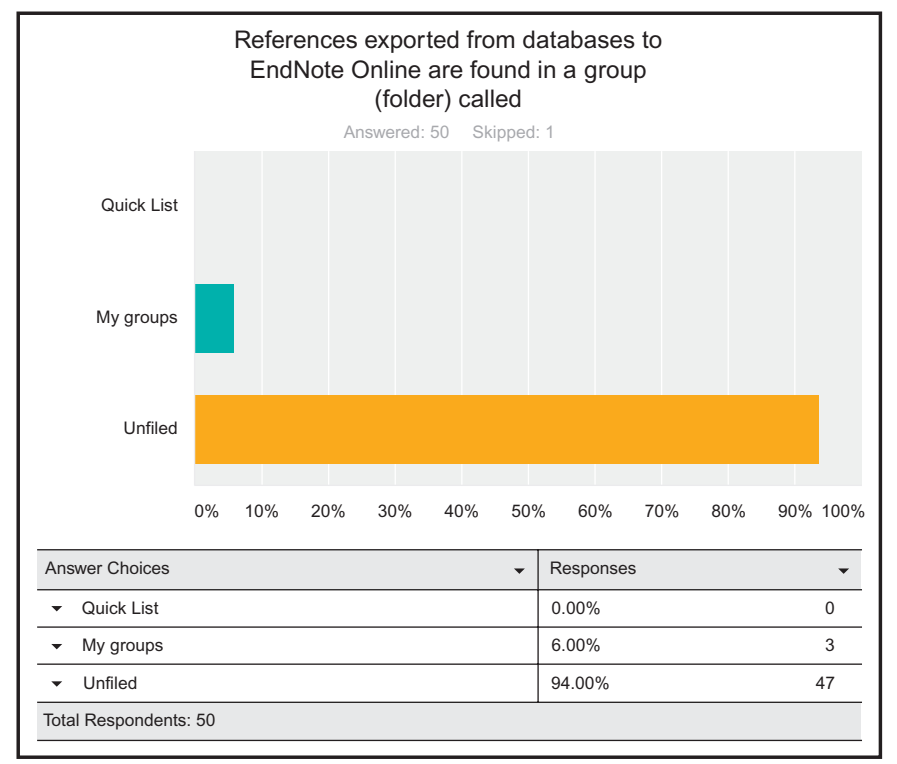

Figure 6.7 Screen capture from an assignment (in SurveyMonkey) for a chemistry course. Students had to say where references exported directly from databases are found in EndNote. The correct answer is "Unfiled."

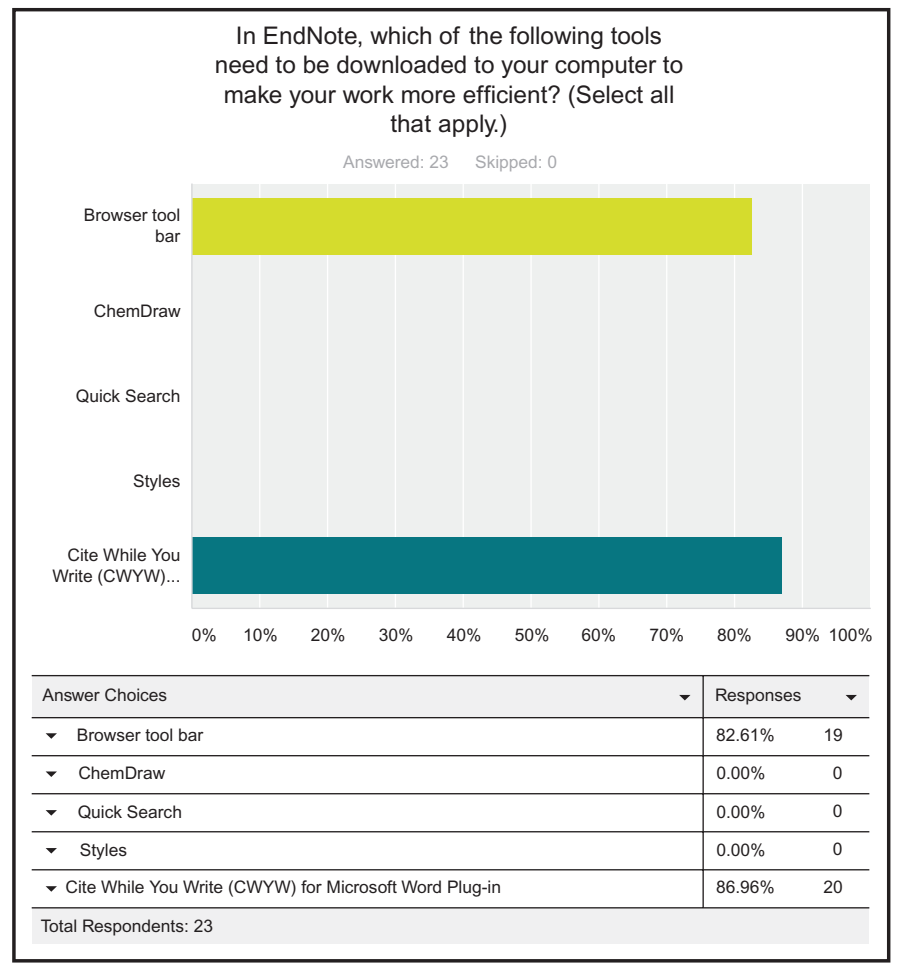

Figure 6.8 Screen capture from an assignment (in SurveyMonkey) that students in a chemistry course had to submit. There are two correct answers: "Browser toolbar" and "Word Plug-in." 


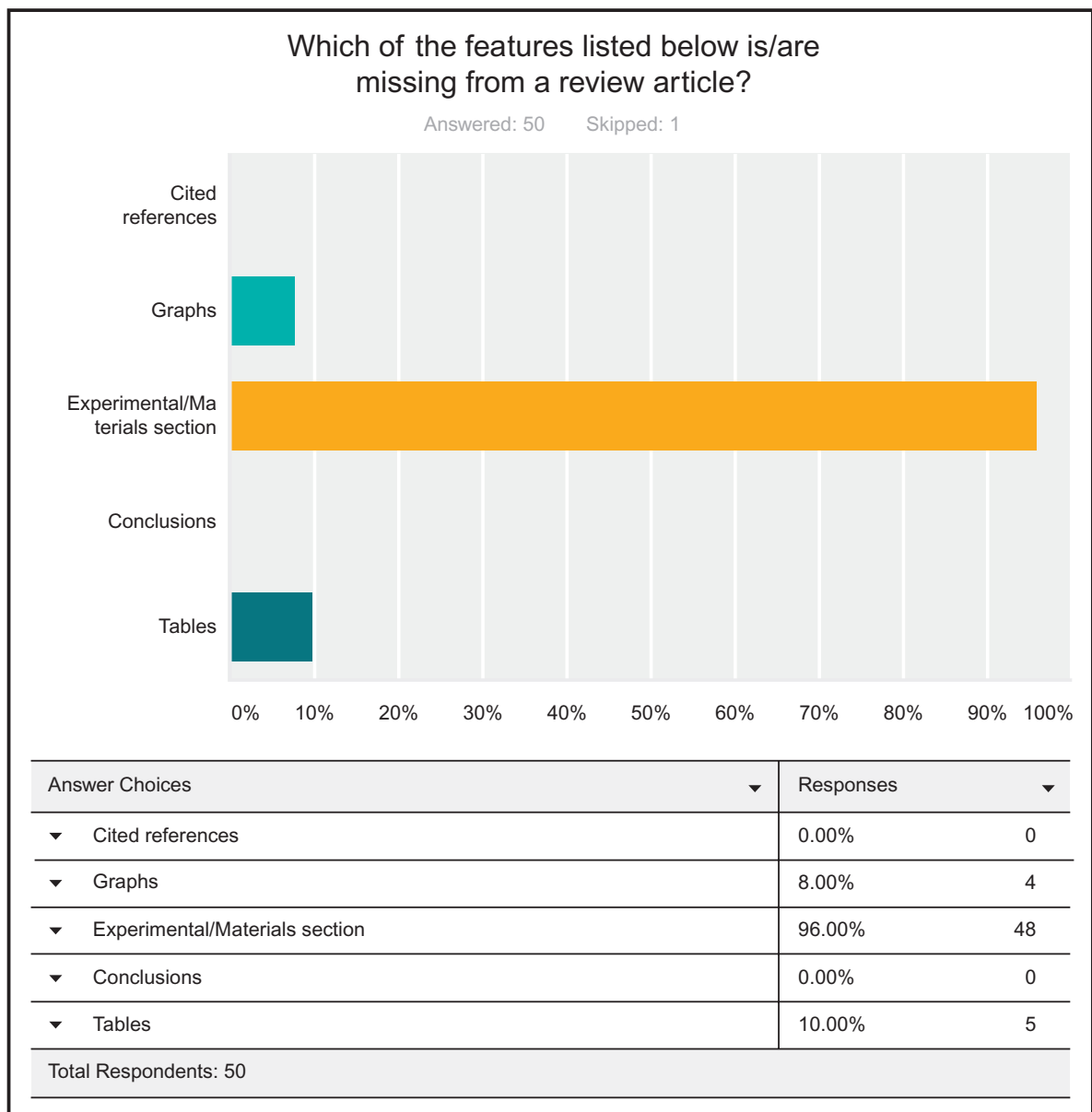

Figure 6.9 Assignment question about the difference between a research paper and a review paper. The correct answer is "Experimental/Materials section."

preferred blended instruction, and only a small percentage wanted completely online instruction. As shown in Figure 6.11, students in a chemistry course (CHEM277) for chemistry majors ranked the in-class presentation as most useful, followed by the online handout prepared for the class.

Responses from students in another course about the preferred format for information literacy instruction showed that face-to-face instruction was the preferred format $(67 \%)$, followed by "face-to-face and online tutorial" (42\%) (Figure 6.12). Only 4\% of students preferred the online only format. The question was included in an assignment for a course (UNIV100, Integrated Life Sciences) in the University of Maryland College Park. 


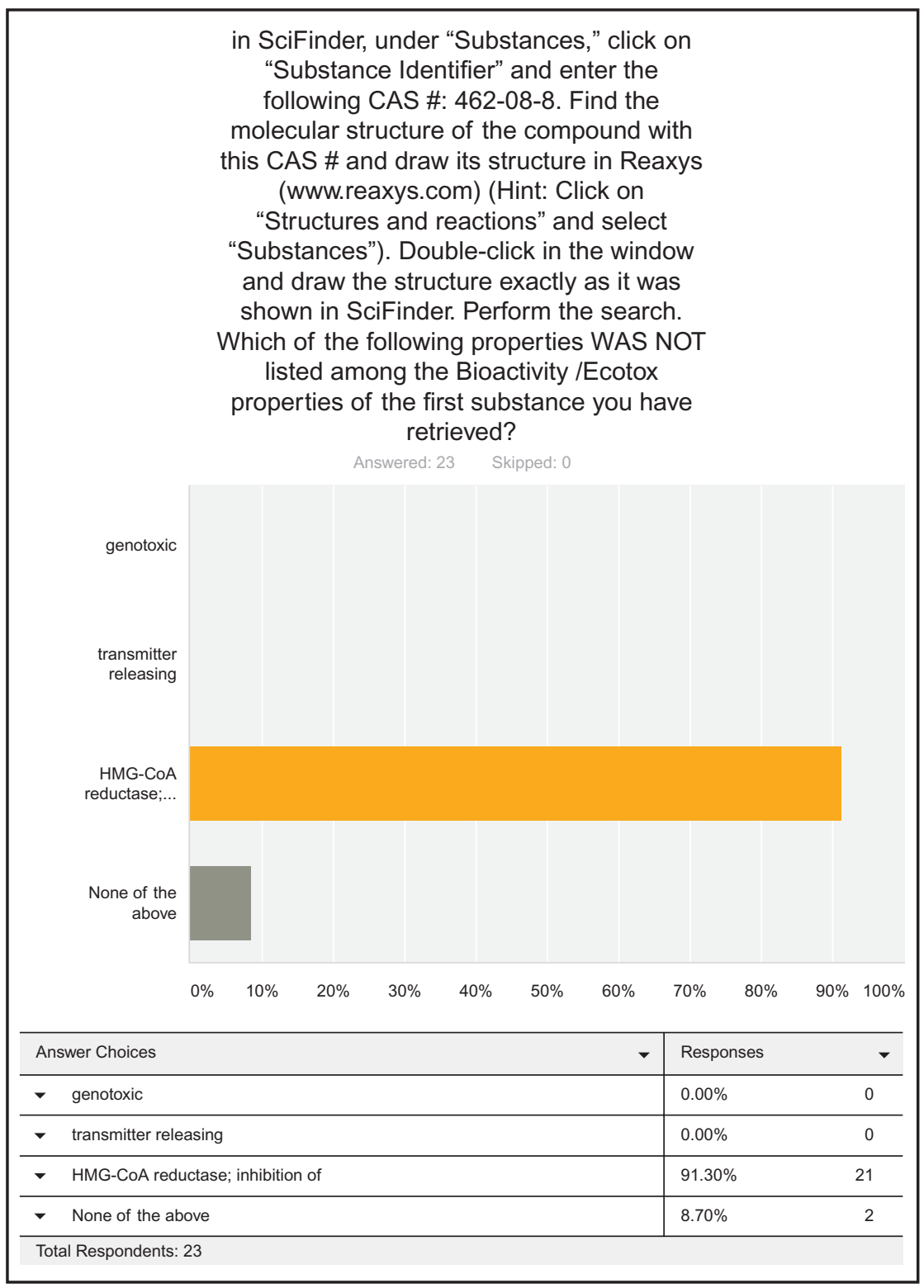

Figure 6.10 Students were asked to (1) search for a chemical compound in SciFinder, using its CAS number; (2) find the molecular structure of that compound and draw its structure in another database, Reaxys; (3) look at the bioactivity/ecotoxicity properties of the first retrieved compound; and (4) choose which of the properties listed under the question was not associated with this compound. The correct answer is "HMG-CoA reductase, inhibition of." 


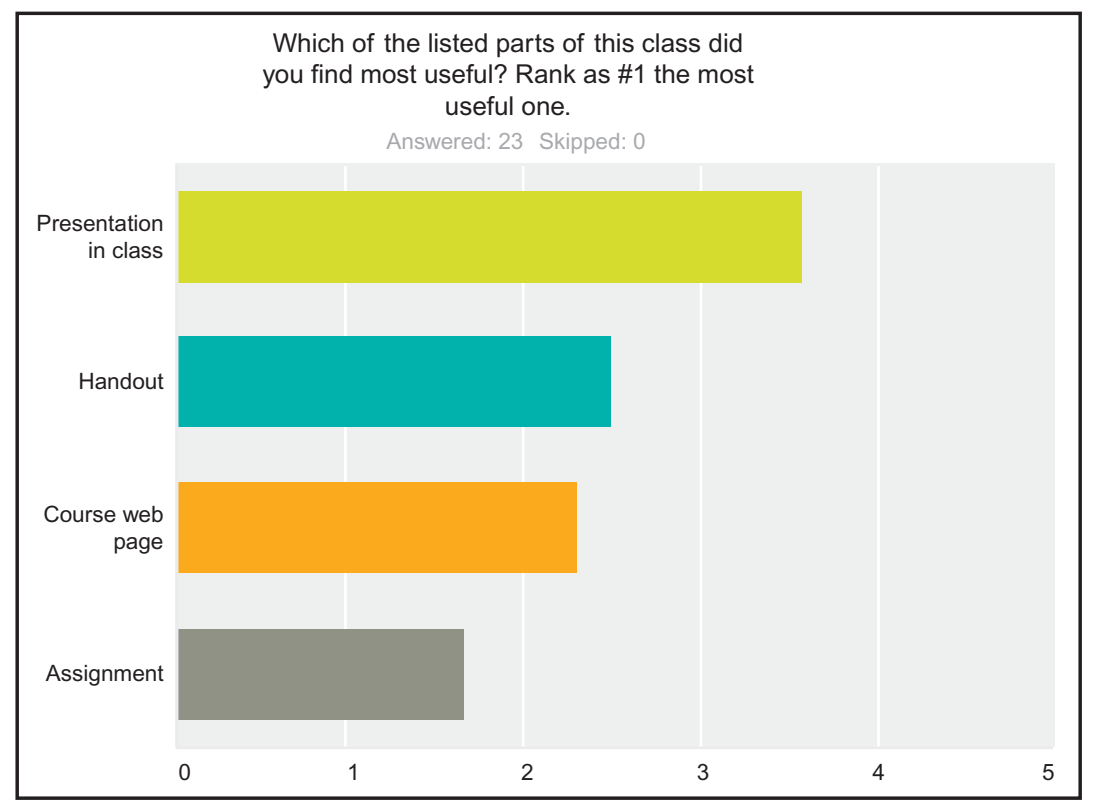

Figure 6.11 Responses from students in a 200-level chemistry course for chemistry majors to a question about which component of the information literacy instruction they found most useful. The question was included in an assignment that students had to complete in February 2014.

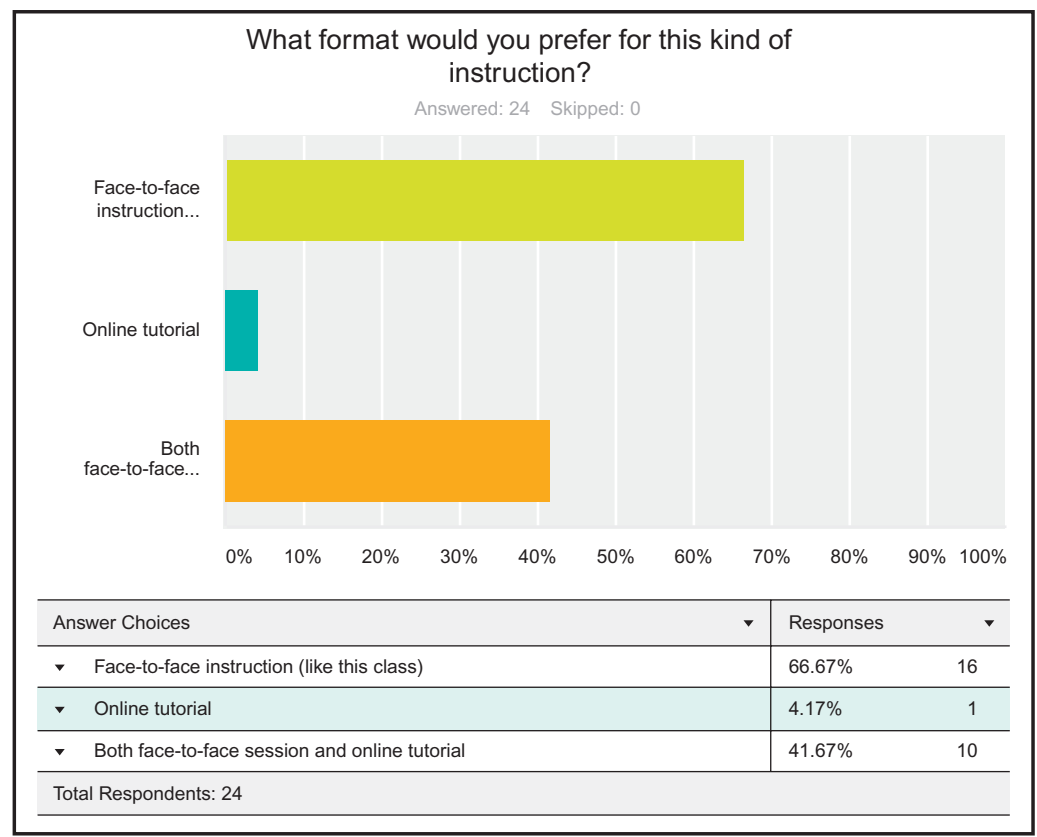

Figure 6.12 Responses from students about preferred format for information literacy instruction. The question was included in an assignment for a course (UNIV100, Integrated Life Sciences) in the University of Maryland College Park. Face-to-face instruction was the most preferred format (67\%), followed by "face-to-face and online tutorial" (42\%). Only 4\% of students preferred online (only) format. 


\subsection{Other elements of information literacy}

As the importance of research data is increasing, eScience has emerged as a new opportunity for academic libraries to support research and education in their institutions. Helping researchers manage their data and integrating data literacy in library instruction will be the main areas of engagement for librarians in the future (Qin and D'Ignazio, 2010). The advancement of data literacy will depend on identifying and developing core competencies and standards that can serve as a framework for its inclusion in libraries' information literacy programs (Prado and Marzal, 2013; Vogt, 2013). The roles of librarians in supporting eScience, in general, and data literacy, in particular, is covered in more detail in Chapter 8.

Academic librarians now discuss in their information literacy classes other areas such as scientific communication, Open Access, new forms of publishing, ethics of scientific publishing, scientific impact, social networks, and altmetrics. These topics are covered in other chapters of this book.

All assignment examples are from chemistry courses taught at the University of Maryland College Park. Screen captures from assignments are reproduced with permission from SurveyMonkey.

\subsection{Sample questions for assignments in science courses}

1. Adding an asterisk $(*)$ at the end of a word would allow you to retrieve:

- More articles

- Fewer articles

- Specific articles

2. After performing a search in a database, which of the following actions will reduce the number of results? (Select all that apply.)

- Selecting a range of publication year(s)

- Adding additional keywords

- Choosing a particular document type (e.g. review)

- All of the above

3. Which of the following actions will allow you to expand your search?

- Putting an asterisk $(*)$ after a word

- Using specific terms

- Using broader terms

- Using a larger number of keywords

- All of the above

- None of the above

4. Which of the features listed below is/are missing from a review article?

- Cited references

- Graphs

- Experimental/Materials section

- Conclusions

- Tables 
5. In PubMed, (1) click on the "Advanced" option; (2) type ENZYME INHIBITORS in the first box. (3) Select "MESH Major Topic" from the pull-down menu on the left of this box; (4) click on "Show index list" on the right of the box; (5) double-click on "Enzyme inhibitors." (6) In the second box, type CHOLESTEROL; (7) from the pull-down menu on the left of this box, select "MESH Term." (8) Click on "Show index list" on the right of the box; (9) double-click on "Cholesterol"; (10) perform the search and limit it by time period (Hint: select "Custom") to the time period from 1/1/2009 to 12/31/2010. Select "Review" under "Article types." How many documents were retrieved for this time period?

- 111

- 246

- 18

- 308

- None of the above

6. In Web of Science, enter "aspirin and cancer" (no quotation marks) as a topic. In the box under "Refine Results," type "treatment" and click on the magnifier on the right of the box; on the next screen, check the box next to "Oncology" under "Web of Science categories," and click on "Refine." Narrow down the results by publication year, from 2009 to 2012 (Hint: make the years chronological by changing "Record count" to "Alphabetical"). How many documents were retrieved for this time period? Enter the answer in the box.

- 204

- 15

- 43

- 120

- None of the above

7. After performing a search in SciFinder, which of the following actions is important to perform to narrow down the number of results (select all that apply)?

- Refine the list by publication year

- Remove duplicates

- Add additional keywords

- Limit to a particular document type (e.g. review)

- All of the above

8. Perform a search for properties of aspirin in SciFinder (Hint: Go to "Substance identifier"; then on the next screen, click on the aspirin CAS number.) What is the melting point (experimental) for aspirin (in degrees Celsius)?

- 135

- 138

- 145

- 164

- None of the above

9. In SciFinder, perform a search on a topic (use "Explore References") and type "enzyme inhibitors AND cholesterol" (without the quotation marks) in the search box. From the options you were presented with, which one would be best to choose?

- References were found containing "enzyme inhibitors and cholesterol" as entered.

- References were found containing both of the concepts "enzyme inhibitors" and "cholesterol."

- References were found containing either the concept "enzyme inhibitors" or the concept "cholesterol."

- References were found containing the concept "enzyme inhibitors."

- References were found containing the concept "cholesterol." 
10. In SciFinder, under "Substances," click on "Substance Identifier" and enter the following CAS \#: 462-08-8. Find the molecular structure of the compound with this CAS \# and draw its structure in Reaxys (www.reaxys.com) (Hint: Click on "Substances, Names, Formulas" and select "Substances"). Double-click in the query editor window on the left of the screen and draw the structure exactly as it was shown in SciFinder. (If you have a problem opening the drawing window (it is Java-based), click on "Structure editor" at the bottom of this window and select "Dotmatics Elemental.") After drawing the structure, click on "Transfer Query" and click on "Search." Which of the following properties was not listed among the bioactivity properties of the first substance you have retrieved?

- Genotoxic

- Transmitter-releasing

- HMG-CoA reductase, inhibition of

- None of the above

11. In Reaxys, click on "Substances, Names \& Formulas," select "Substances," and type the following CAS \# in the appropriate box: 504-24-5. This CAS \# corresponds to which of the following chemical compounds?

- Cholesterol

- Toluene

- Arachidonic acid

- 4-Aminopyridine

- None of the above

12. Use the Advanced Search option in ChemSpider; check the box next to "Select by Properties." Select "Molecular Formula" and enter the following empirical formula: C33H35FN2O5. To which of the following substances does this formula correspond to?

- Lovastatin

- Lisinopril

- Crestor

- Atorvastatin

13. In PubChem, find property information for 3-aminopyridine. Which of the following numbers corresponds to the molecular weight (in $\mathrm{g} / \mathrm{mol}$ ) of this compound as listed under "Computed Properties" in the "Chemical and Physical Properties" section?

- 96.12908

- 94.12356

- 94.11454

- 94.23901

14. Perform a search in Scopus using the following string of search terms: "reverse transcriptase and HIV and hepatitis B" (no quotation marks). Limit the results to the year 2010. Which source title (journal) has published the highest number of articles on this topic in this particular year?

- The Journal of Immunology

- AIDS

- Antiviral Therapy

- None of the above 
15. Perform a search in Scopus using "hplc fatty acids" as search terms (without the quotation marks). How many review articles were published on this topic in the year 2009 ?

- 83

- 121

- 51

- 14

- 8

- None of the above

16. Which of the resources shown in class were most useful to you? The most useful would be " 1 ."

- EndNote

- PubMed

- Reaxys

- SciFinder

- Scopus

- Web of Science

17. Select from the list below the resources about which you have learned for the first time in this class.

- PubChem

- PubMed

- SciFinder

- Reaxys

- Scopus

- Web of Science

18. References imported directly from databases to EndNote Web will be placed in

- Quick List

- Unfiled

- Trash

- None of the above

19. Perform a search in Scopus using the following keywords: "plant physiology and drought" (no quotation marks). Refine your results by adding "fungal" as an additional topic. Limit your results to those published in the year 2010. How many articles were published in the "Journal of Plant Physiology" for that year?

- 203

- 16

- 8

- 37

- None of the above

20. Perform a search in Agricola on the EBSCO platform. Type "plant physiology" in the first box and "drought" in the second box (no quotation marks). Refine your search to SCHOLARLY ARTICLES and to the time period 2002-2006. How many articles were published during this time period?

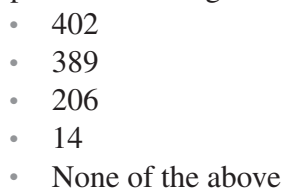


21. If you could choose the format of this kind of instruction, which of the following options would you prefer?

- Face-to-face instruction with online tutorials (like this class)

- Online tutorial only

22. Did you find this class and the assignment useful and why? Was the assignment difficult to do and how long did it take you to do it?

\section{References}

Baykoucheva, S., 2011. Using Campus Guides for leveraging Web 2.0 technologies and promoting the chemistry and life sciences information resources. In: Abstracts of Papers, 241st ACS National Meeting \& Exposition, Anaheim, CA, United States, March 27-31, 2011, CINF-50.

Bennett, S., 2007. Campus cultures fostering information literacy. portal Libr. Acad. 7 (2), 147-67.

Brasley, S.S., 2008. Effective librarian and discipline faculty collaboration models for integrating information literacy into the fabric of an academic institution. New Dir. Teach. Learn. 2008 (114), 71-88.

Brewerton, A., 2012. Re-skilling for research: investigating the needs of researchers and how library staff can best support them. New Rev. Acad. Librarian. 18 (1), 96-110. http://dx.doi. org/10.1080/13614533.2012.665718.

Duarte-García, E., 2007. Personal managers of bibliographic reference data bases: characteristics and comparative analysis. Prof. Inf. 16 (6), 647-56. http://dx.doi.org/10.3145/ epi.2007.nov.12.

Fenner, M., Scheliga, K., Bartling, S., 2014. Reference management. Opening Science. Retrieved from http://book.openingscience.org/tools/reference_management.html.

Habib, M., 2014. Mendeley Readership Statistics available in Scopus. Retrieved from http:// blog.scopus.com/posts/mendeley-readership-statistics-available-in-scopus.

Haustein, S., 2014. Tweets and Mendeley readers: two different types of article level metrics. Retrieved July 2, 2014, from http://www.slideshare.net/StefanieHaustein/ haustein-ape2014-30482551.

Hull, D., Pettifer, S.R., Kell, D.B., 2008. Defrosting the Digital Library: Bibliographic Tools for the Next Generation Web. PLoS Comput Biol 4 (10), e1000204. http://dx.doi.org/10.1371/ journal.pcbi.1000204.

McKinney, A., 2013. EndNote Web: web-based bibliographic management. JERML 10 (4), 185-92. http://dx.doi.org/10.1080/15424065.2013.847693.

McMillen, P., Fabbi, J., 2010. How to be an $\mathrm{E}^{3}$ librarian. Public Serv. Q. 6 (2-3), 174-86.

Olivares, O., 2010. The sufficiently embedded librarian: defining and establishing productive librarian-faculty partnerships in academic libraries. Public Serv. Q. 6 (2-3), 140-9.

Prado, J.C., Marzal, M.A., 2013. Incorporating data literacy into information literacy programs: core competencies and contents. Libri 63 (2), 123-34.

Qin, J., D'Ignazio, J., 2010. The central role of metadata in a science data literacy course. J. Libr. Metadata 10 (2-3), 188-204.

Saunders, L., 2009. The future of information literacy in academic libraries: a Delphi study. portal Libr. Acad. 9 (1), 99-114.

Thomson Reuters, 2014. EndNote. Retrieved from http://www.endnoteweb.com.

Travis, T.A., 2008. Librarians as agents of change: working with curriculum committees using change agency theory. New Dir. Teach. Learn. 2008 (114), 17-33. 
Vogt, L., 2013. eScience and the need for data standards in the life sciences: in pursuit of objectivity rather than truth. Syst. Biodivers. 11 (3), 257-270.

Wikipedia, 2014. Comparison of reference management software. Retrieved from https:// en.wikipedia.org/wiki/Comparison_of_reference_management_software.

York, A.C., Vance, J.M., 2009. Taking library instruction into the online classroom: best practices for embedded librarians. J. Libr. Adm. 49 (1/2), 197-209. http://dx.doi. org/10.1080/01930820802312995.

Zhang, Y., 2012. Comparison of select reference management tools. Med. Ref. Serv. Q. 31 (1), 45-60. http://dx.doi.org/10.1080/02763869.2012.641841. 